\title{
Elderly patients with myocardial infarction selected for conservative or invasive treatment strategy
}

\author{
Berglind Libungan' \\ Thomas Karlsson ${ }^{2}$ \\ Per Albertsson' \\ Johan Herlitz ${ }^{3}$ \\ 'Department of Cardiology, \\ Sahlgrenska University Hospital, \\ Gothenburg, Sweden; ${ }^{2}$ Center \\ for Applied Biostatistics, Occupational \\ and Environmental Medicine, \\ Sahlgrenska Academy at University \\ of Gothenburg, Gothenburg, Sweden; \\ ${ }^{3}$ Sahlgrenska University Hospital and \\ Center for Prehospital Research, \\ Western Sweden University of Borås, \\ Borås, Sweden
}

This article was published in the following Dove Press journal:

Clinical Interventions in Aging

21 January 2015

Number of times this article has been viewed

Background: There are limited data on patients aged $>75$ years with myocardial infarction (MI), especially those who are treated conservatively.

Hypothesis: There are important differences in the clinical characteristics and outcome between elderly MI patients selected for invasive or conservative treatment strategy.

Methods: A total of 1,413 elderly patients ( $>75$ years old) admitted to Sahlgrenska University Hospital, Gothenburg, Sweden with a final diagnosis of acute MI in 2001 or 2007, were divided into two groups, those who underwent a conservative treatment strategy (conservative group [CG], $n=1,169$ ) and those who underwent coronary angiography and were revascularized if indicated (invasive group [IG], $\mathrm{n}=244$ ).

Results: Other than higher age in the CG, there were no significant differences in traditional risk factors such as hypertension, diabetes, and smoking in the two groups. A higher proportion of patients in the CG had a history of heart failure and cerebrovascular disease. The hazard ratio (with 95\% confidence interval), adjusted for potential confounders, for 5 year mortality in the IG in relation to the CG was $0.49(0.39,0.62), P<0.0001$. Overall, in the elderly with MI, the proportion who underwent an invasive treatment strategy doubled from $12 \%$ in 2001 to $24 \%$ in 2007, despite a slightly higher mean age.

Conclusion: Elderly patients with MI in the CG (no coronary angiography), were generally older and a higher proportion had chronic diseases such as congestive heart failure and cerebrovascular disease than those in the IG. Our data suggest that the invasive treatment strategy is associated with better outcome. However, randomized trials will be needed to determine whether revascularization procedures are beneficial in elderly patients with MI, in terms of less symptoms, better outcome, and improved quality of life.

Keywords: elderly, myocardial infarction, acute coronary syndrome, aged

\section{Introduction}

Clinicians can be faced with difficult decisions regarding elderly patients with myocardial infarction (MI). One basic but major medical decision is whether or not to perform a coronary angiography, due to unclear benefit associated with revascularization ${ }^{1}$ and also higher risk. ${ }^{2,3}$

According to large clinical trials, ${ }^{4,5}$ revascularization with percutaneous coronary intervention $(\mathrm{PCI})$ or coronary artery bypass graft $(\mathrm{CABG})$ in patients with $\mathrm{MI}$ rather than a less aggressive medical treatment approach leads to better outcomes and is generally accepted as standard. But this does not necessarily hold true for certain subsets of under-represented groups in clinical trials, such as the elderly. This gap in evidence-based medicine can partly be explained by the fact that elderly patients often meet exclusion criteria in studies due to comorbidity, or due simply to exceeding the upper age limit. ${ }^{6}$
Correspondence: Berglind Libungan Sahlgrenska University Hospital,

Department of Cardiology,

Blå stråket 3 , vån $\mathrm{I}, \mathrm{SE}-4 \mathrm{I} 345$

Gothenburg, Sweden

Email berglind.libungan@vgregion.se 
Observational studies without consecutive enrollment tend to have fewer elderly patients included, especially those with high comorbidity, leading to risk of selection bias.

How clinicians treat the elderly with MI is often done on a case-to-case basis, since old people are a very heterogeneous group. The clinical setting, comorbid diseases, cognitive function, and patient preference are factors that often influence the decision-making process. ${ }^{7}$

There is no ideal dedicated calculator of risk in the elderly, and in the general ones - eg, the GRACE (Global Registry of Acute Coronary Events) ACS (acute coronary syndrome) risk model $^{8}-$ advanced age is associated with worse outcome in terms of mortality. But risk of procedure-related complications and benefit in terms of less symptoms and better quality of life, which are important factors in the elderly, can be difficult to assess in individual elderly MI patients.

The aim of the present study was to explore differences between elderly MI patients selected for invasive or conservative treatment strategy regarding previous history, clinical presentation, in-hospital events, and long-term mortality of elderly patients with MI.

\section{Materials and methods Location of study}

Gothenburg is the second largest city in Sweden with approximately half a million inhabitants. The total population of Sweden is around 9 million.

\section{Patients}

All patients admitted to Sahlgrenska University Hospital in Gothenburg were screened retrospectively using the Swedish National Patient Register in two different 1 year time periods, 2001 (2001-2002) and 2007. Patients who were given the discharge diagnosis of acute MI (both STelevation MI or non-ST-elevation MI) were evaluated for inclusion.

\section{Inclusion criteria}

The following three conditions were required: 1) living in the city of Gothenburg, 2) hospitalized alive between 1 July 2001 and 30 June 2002, or between 1 January and 31 December 2007, 3) given a discharge diagnosis of acute MI, and 4) aged over 75 years (ie, had at least reached their 75 th birthday).

\section{Exclusion criteria}

There were no exclusion criteria.

\section{Definitions}

Conservative treatment strategy: patients who did not undergo coronary angiography during their first hospitalization.
Invasive treatment strategy: patients who underwent coronary angiography, followed by revascularization if indicated (PCI or CABG), during their first hospitalization. The decision whether to treat the patient with the invasive treatment strategy or not was made by the treating physicians, who were not aware of this study (retrospective data collection).

\section{Previous history}

Smoking: regular smoking or stopped smoking less than 30 days prior to hospital admission.

Previous MI: documented previous MI or silent MI on electrocardiogram (ECG).

Previous angina pectoris: angina pectoris with duration of 3 weeks or more prior to hospitalization. Patients with stable angina pectoris, unstable angina pectoris, symptoms equivalent to angina pectoris, syndrome $\mathrm{X}$, and chest pain where nitroglycerin had an immediate pain relieving effect were also considered.

Peripheral vascular disease: intermittent claudication, peripheral bypass surgery, abdominal or thoracic aortic aneurysm, carotid stenosis or previous carotid endarterectomy. Previous peripheral vessel angioplasty, extremity gangrene, acute artery insufficiency, non-invasive or invasive vascular study documenting peripheral vessel disease.

Cerebrovascular disease: a history of a transient ischemic attack or stroke.

Connective tissue disease: examples: systemic lupus erythematosus disseminatus, scleroderma, dermatomyositis, rheumatic diseases etc.

Renal disease: known previous renal disease or elevated creatinine.

ECG criteria: the ECG definition of acute myocardial ischemia in the absence of left bundle branch block, right bundle branch block, and pacemaker rhythm with new ST-elevation at the $\mathrm{J}$ point in two contiguous leads with the cut-off points of $1 \mathrm{~mm}(0.1 \mathrm{mV})$ in all leads other than leads $\mathrm{V}_{2}-\mathrm{V}_{3}$, where the cut-off points of $2 \mathrm{~mm}(0.2 \mathrm{mV})$ in men and $\geq 1.5 \mathrm{~mm}(0.15 \mathrm{mV})$ in women apply. In cases of ST-segment depression, those regarded as manifestations of acute myocardial ischemia were a down-sloping ST segment with J-point depression of $0.5 \mathrm{~mm}(0.05 \mathrm{mV})$ in at least two contiguous leads. "Contiguous leads" refers to anterior leads $\left(\mathrm{V}_{1}-\mathrm{V}_{6}\right)$, inferior leads (II, III, aVF), or lateral/apical leads (I, aVL).

\section{Events in hospital and during follow-up}

Congestive heart failure: by clinical diagnosis. 
Cardiogenic shock: this was defined if any of the following three conditions applied: 1) systolic blood pressure below $80 \mathrm{mmHg}$ in ambulance or on admission to hospital; 2) cardiogenic shock was mentioned in the case record forms; or 3) patients required inotropic medication in order to maintain systolic blood pressure above $80 \mathrm{mmHg}$.

Hypotension: systolic blood pressure below $80 \mathrm{mmHg}$ on two or more occasions or with at least a 5 minute interval, or treatment with an aortic balloon pump or inotropic drug therapy due to hemodynamic instability.

Death: information regarding date of death or confirmation of survival was obtained from the Swedish National Population Registry.

\section{Statistical methods}

All percentages are presented as crude results (ie, not adjusted for age). When we compared age between treatment groups (Table 1), Mann-Whitney $U$-test was used. All other $P$-values were age-adjusted using multiple logistic regression. Multiple logistic regression was also used for analysis of time period by treatment approach interaction.
The Kaplan-Meier method was used for estimation of 5 year survival. For calculation of hazard ratio with corresponding 95\% confidence interval (adjusted for all variables in Table 1 and also for heart failure and chest pain at presentation), Cox proportional hazards model was used. For survival analysis, only the first admission for those with multiple visits was included. All tests were two-sided, and $P$-values below 0.01 were considered statistically significant. All analyses were performed using SAS v9.3 software (SAS Institute Inc., Cary, NC, USA).

\section{Results}

In total, 1,413 elderly patients were included, 1,169 in the conservative group (CG) (year 2001: 706 patients; year 2007: 463 patients) and 244 in the invasive group (IG) (year 2001: 97 patients; year 2007: 147 patients). The oldest patients in the CG were 99 years old and those in the IG were 93 years old.

In 2007, the percentage of patients in the IG doubled and they turned out to be older (mean age 81 years in 2007 as compared to 79 years in 2001). Other than age, traditional risk

Table I Age, sex, and previous history (\%, unless otherwise stated)

\begin{tabular}{|c|c|c|c|c|c|c|c|c|}
\hline & \multicolumn{2}{|l|}{2001} & \multicolumn{2}{|l|}{2007} & \multicolumn{2}{|l|}{$2001+2007$} & \multirow[t]{2}{*}{$P *$} & \multirow[t]{2}{*}{ P** } \\
\hline & $\begin{array}{l}\text { Cons } \\
(n=706)\end{array}$ & $\begin{array}{l}\text { Inv } \\
(n=97)\end{array}$ & $\begin{array}{l}\text { Cons } \\
(n=463)\end{array}$ & $\begin{array}{l}\text { Inv } \\
(n=\mid 47)\end{array}$ & $\begin{array}{l}\text { Cons } \\
(n=I, 169)\end{array}$ & $\begin{array}{l}\text { Inv } \\
(n=244)\end{array}$ & & \\
\hline Age (mean $\pm S D ;$ years) & $84 \pm 5$ & $79 \pm 3$ & $85 \pm 5$ & $8 I \pm 4$ & $84 \pm 5$ & $80 \pm 4$ & $<0.0001$ & 0.33 \\
\hline Women & 53 & 40 & 57 & 46 & 55 & 43 & 0.053 & 0.83 \\
\hline \multicolumn{9}{|l|}{ Past medical history } \\
\hline \multicolumn{9}{|l|}{ Risk factors for AMI } \\
\hline Hypertension & 54 & 59 & $57^{a}$ & $59^{a}$ & $55^{\mathrm{a}}$ & $59^{a}$ & 0.48 & 0.71 \\
\hline Diabetes & 21 & 20 & 28 & 24 & 24 & 22 & 0.18 & 0.69 \\
\hline Smoking at time of arrival & $10^{c}$ & 14 & 7 & $\mathrm{I} \mathrm{I}^{\mathrm{a}}$ & $9^{b}$ & $12^{\mathrm{a}}$ & 0.64 & 0.89 \\
\hline \multicolumn{9}{|l|}{ Previous heart disease } \\
\hline Acute myocardial infarction & 44 & $3 I^{a}$ & 44 & 36 & 44 & 34 & 0.03 & 0.59 \\
\hline Angina pectoris & 48 & 38 & $3 I^{a}$ & $32^{\mathrm{a}}$ & $4 l^{a}$ & $35^{\mathrm{a}}$ & 0.34 & 0.19 \\
\hline Cardiac arrest & $\rho^{\mathrm{a}}$ & 2 & 0 & $0^{\mathrm{a}}$ & $<\mathrm{I}$ & $<1$ & 1.00 & - \\
\hline CABG & 8 & 6 & 12 & $14^{\mathrm{a}}$ & 10 & II & 0.41 & 0.37 \\
\hline $\mathrm{PCl}$ & 3 & 8 & 7 & $19^{a}$ & 4 & 14 & $<0.0001$ & 0.76 \\
\hline Congestive heart failure & 44 & 16 & 36 & II & 41 & 13 & $<0.0001$ & 0.69 \\
\hline Atrial fibrillation & 29 & 8 & 27 & $20^{a}$ & 28 & $15^{\mathrm{a}}$ & 0.001 & 0.003 \\
\hline \multicolumn{9}{|l|}{ Other vascular disease } \\
\hline Peripheral vascular disease & $14^{\mathrm{a}}$ & 20 & 13 & 9 & 14 & 13 & 0.44 & 0.04 \\
\hline Cerebrovascular disease & 25 & 12 & 24 & 13 & 24 & 13 & 0.0002 & 0.77 \\
\hline \multicolumn{9}{|l|}{ Other disease } \\
\hline COPD & 12 & 10 & 13 & 10 & 12 & 10 & 0.03 & 0.67 \\
\hline Connective tissue disease & 3 & 0 & 0 & 0 & 2 & 0 & 0.03 & - \\
\hline Non-metastatic tumor & $\mathrm{II}$ & 7 & 6 & 4 & 9 & 5 & 0.09 & 0.82 \\
\hline Metastatic tumor & $6^{\mathrm{a}}$ & 3 & 12 & 6 & 9 & 5 & 0.08 & 0.97 \\
\hline Renal disease & $9^{a}$ & 8 & 13 & 7 & 9 & 7 & 0.08 & 0.27 \\
\hline Treated at hospital with $\mathrm{PCl}$ facilities & 48 & 75 & 55 & 56 & 51 & 64 & 0.003 & 0.0001 \\
\hline
\end{tabular}

Notes: *For difference between conservative and invasive treated groups (age adjusted); ${ }^{* *}$ for time period by treatment interaction; ${ }^{\text {al} \%-5 \% ~ m i s s i n g ; ~}{ }^{\circ} \%$ - $10 \%$ missing; c10\%-25\% missing.

Abbreviations: Cons, conservative; Inv, invasive; SD, standard deviation; CABG, coronary artery bypass graft; PCl, percutaneous coronary intervention; COPD, chronic obstructive pulmonary disease; AMI, acute myocardial infarction. 
factors such as hypertension, diabetes, and smoking were not significantly different in the IG and the CG (Table 1).

Patients who were treated at a hospital with PCI facilities had a higher proportion of elderly patients who underwent a coronary angiogram, $21 \%$ versus (vs) 13\%, $P=0.003$.

Only one patient was lost to follow-up (at 355 days), due to emigration. Two patients (one in 2001 and one in 2007) underwent an in-hospital CABG but had coronary angiography performed before hospitalization, therefore meeting the criteria for inclusion in the CG. The difference between the IG and CG regarding prior atrial fibrillation was significantly smaller in 2007 than in 2001 ( $P=0.003$ for time period by treatment interaction).

\section{Factors defining the CG}

The patients in the CG were generally older, had more comorbid disorders, and had poorer outcome than those in the IG. More patients in the CG had previous congestive heart failure and cerebrovascular disease than the patients in the IG. There were no significant differences regarding the other co-morbidities studied (cancer, renal disease, and connective tissue disease). Previous history of congestive heart failure was more than three times higher in the CG than in the IG (41\% vs $13 \%, P<0.0001)$.

Also, a lower percentage of patients in the CG had typical symptoms and signs of MI, such as chest pain (76\% vs
$93 \%, P<0.0001)$ and ECG with ST-elevation indicating myocardial ischemia ( $8 \%$ vs $26 \%, P<0.0001$ ), as shown in Table 2.

\section{Treatment was shifting towards $\mathrm{PCl}$}

A higher proportion of elderly patients were treated with PCI in 2007 than in 2001, and thrombolytic therapy was almost non-existent in 2007.

\section{Outcome}

In-hospital death and events such as pneumonia and congestive heart failure were more common in the $\mathrm{CG}$ than in the IG (Table 3). More than one third of the patients in the $\mathrm{CG}$ had congestive heart failure during hospitalization but the corresponding proportion for the IG was less than one fifth $(P<0.0001)$. The unadjusted Kaplan-Meier survival estimates in the IG and CG for each time period are shown in Figure 1. When we adjusted for potential confounders, as described in Statistical methods, there was a significant difference regarding 5 year mortality in favor of the IG (hazard ratio 0.49 , 95\% confidence interval $0.39-0.62$, $P<0.0001)$.

\section{Discussion}

In this study of elderly patients hospitalized for MI, we found differences in previous history, presentation, in-hospital

Table 2 Presentation (\%)

\begin{tabular}{|c|c|c|c|c|c|c|c|c|}
\hline & \multicolumn{2}{|l|}{2001} & \multicolumn{2}{|l|}{2007} & \multicolumn{2}{|l|}{$200 I+2007$} & \multirow[t]{2}{*}{$P^{*}$} & \multirow[t]{2}{*}{$P * *$} \\
\hline & $\begin{array}{l}\text { Cons } \\
(n=706)\end{array}$ & $\begin{array}{l}\text { Inv } \\
(n=97)\end{array}$ & $\begin{array}{l}\text { Cons } \\
(n=463)\end{array}$ & $\begin{array}{l}\text { Inv } \\
(n=\mid 47)\end{array}$ & $\begin{array}{l}\text { Cons } \\
(n=1,169)\end{array}$ & $\begin{array}{l}\text { Inv } \\
(n=244)\end{array}$ & & \\
\hline \multicolumn{9}{|l|}{ Symptoms } \\
\hline Chest pain/pressure/discomfort & $81^{a}$ & 98 & $68^{a}$ & 90 & $76^{a}$ & 93 & $<0.000 \mathrm{I}$ & 0.18 \\
\hline Loss of consciousness & $7^{\mathrm{a}}$ & 5 & 9 & 5 & $8^{\mathrm{a}}$ & 5 & 0.13 & 0.79 \\
\hline $\begin{array}{l}\text { Pulmonary edema or cardiogenic } \\
\text { shock }\end{array}$ & 7 & 5 & 10 & 8 & 8 & 7 & 0.24 & 0.81 \\
\hline \multicolumn{9}{|l|}{ Other at presentation } \\
\hline Cardiogenic shock & $\mathrm{I}^{\mathrm{a}}$ & 0 & $<\mathrm{l}^{\mathrm{a}}$ & 3 & $I^{a}$ & 2 & 0.27 & 0.15 \\
\hline Congestive heart failure & 45 & 15 & $52^{\mathrm{a}}$ & $27^{a}$ & $48^{\mathrm{a}}$ & $22^{\mathrm{a}}$ & $<0.0001$ & 0.28 \\
\hline ECG recording available ${ }^{\#}$ & 46 & 77 & 85 & 84 & $6 I$ & 82 & $<0.000$ I & 0.0001 \\
\hline ST elevation & 9 & 23 & 7 & 28 & 8 & 26 & $<0.0001$ & 0.15 \\
\hline \multicolumn{9}{|l|}{ Location } \\
\hline Anterior & 8 & 20 & 6 & 19 & 7 & 19 & $<0.0001$ & 0.55 \\
\hline Inferior & 2 & 9 & 2 & 15 & 2 & 13 & $<0.0001$ & 0.26 \\
\hline Lateral & 0 & 3 & 0 & 2 & 0 & 3 & 0.0005 & 1.00 \\
\hline ST-depression & 27 & 31 & 25 & 35 & 26 & 33 & 0.008 & 0.45 \\
\hline LBBB & 15 & 8 & 15 & 8 & 15 & 8 & 0.005 & 0.96 \\
\hline Other pathological ECG changes & 50 & 59 & 44 & 49 & 46 & 53 & 0.09 & 0.74 \\
\hline Normal ECG & 23 & 20 & 27 & 19 & 25 & 20 & 0.10 & 0.54 \\
\hline Sinus rhythm & 67 & 81 & 68 & 76 & 68 & 78 & 0.07 & 0.45 \\
\hline
\end{tabular}

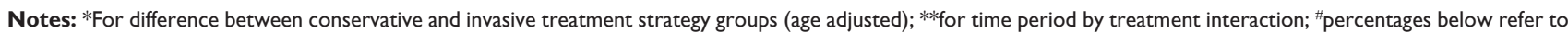
patients with available ECG recordings; ${ }^{a} 1 \%-5 \%$ missing.

Abbreviations: Cons, conservative; Inv, invasive; ECG, electrocardiogram; LBBB, left bundle branch block. 
Table 3 In-hospital procedures and events (\%)

\begin{tabular}{|c|c|c|c|c|c|c|c|c|}
\hline & \multicolumn{2}{|l|}{2001} & \multicolumn{2}{|l|}{2007} & \multicolumn{2}{|l|}{$200 I+2007$} & \multirow[t]{2}{*}{$P *$} & \multirow[t]{2}{*}{$P * *$} \\
\hline & $\begin{array}{l}\text { Cons } \\
(n=706)\end{array}$ & $\begin{array}{l}\operatorname{lnv} \\
(n=97)\end{array}$ & $\begin{array}{l}\text { Cons } \\
(n=463)\end{array}$ & $\begin{array}{l}\text { Inv } \\
(n=\mid 47)\end{array}$ & $\begin{array}{l}\text { Cons } \\
(n=1,169)\end{array}$ & $\begin{array}{l}\text { Inv } \\
(n=244)\end{array}$ & & \\
\hline Thrombolysis & 4 & 16 & $<1$ & 0 & 3 & 7 & 0.04 & 0.18 \\
\hline \multicolumn{9}{|l|}{ Procedures and treatment } \\
\hline Echocardiography & 31 & 82 & 25 & 70 & 29 & 75 & $<0.0001$ & 0.29 \\
\hline Exercise bicycle test & 6 & $20^{\mathrm{a}}$ & 2 & $2^{\mathrm{a}}$ & 4 & $9^{a}$ & 0.61 & 0.08 \\
\hline $\mathrm{PCl}$ & 0 & 42 & 0 & 75 & 0 & 62 & - & - \\
\hline Primary & 0 & $33^{\mathrm{a}}$ & 0 & 65 & 0 & 52 & - & - \\
\hline Rescue & 0 & $7^{a}$ & 0 & 0 & 0 & 3 & - & - \\
\hline Elective & 0 & $I^{a}$ & 0 & 10 & 0 & 6 & - & - \\
\hline CABG & $<1$ & 27 & $<1$ & 7 & $<1$ & 15 & $<0.0001$ & 0.21 \\
\hline \multicolumn{9}{|l|}{ Events } \\
\hline Recurrent AMI & 3 & 6 & 2 & 4 & 2 & 5 & 0.01 & 0.94 \\
\hline Pulmonary embolism & $<\mathrm{l}^{\mathrm{a}}$ & 0 & 2 & 0 & I & 0 & 0.07 & 1.00 \\
\hline Pneumonia & $12^{\mathrm{a}}$ & 6 & 9 & I & $10^{a}$ & 3 & 0.0005 & 0.13 \\
\hline Stroke & $6^{\mathrm{a}}$ & 4 & 3 & $<1$ & 5 & 2 & 0.11 & 0.22 \\
\hline Deep vein thrombosis & $<I^{\mathrm{a}}$ & I & $<1$ & 0 & $<1$ & $<1$ & 1.00 & 0.75 \\
\hline Acute renal failure & $4^{a}$ & 1 & 2 & $<1$ & 4 & $<1$ & 0.055 & 0.91 \\
\hline Hemorrhage requiring transfusion & $4^{a}$ & 0 & 6 & I & 5 & $<1$ & 0.01 & 0.22 \\
\hline Hypotension & $14^{\mathrm{a}}$ & 5 & 16 & 18 & 15 & 13 & 0.35 & 0.02 \\
\hline Pericarditis & $0^{\mathrm{a}}$ & 1 & 0 & $<1$ & 0 & $<1$ & 0.046 & 1.00 \\
\hline Cardiogenic shock & $3^{\mathrm{a}}$ & 3 & 2 & 3 & 2 & 3 & 0.87 & 0.50 \\
\hline Congestive heart failure & 54 & 29 & 19 & 13 & 40 & 19 & $<0.0001$ & 0.11 \\
\hline Death & 20 & 6 & 20 & 10 & 20 & 9 & 0.0003 & 0.31 \\
\hline
\end{tabular}

Notes: *For difference between conservative and invasive treated groups (age adjusted); ${ }^{* *}$ for time period by treatment interaction; ${ }^{\mathrm{a}} \mathrm{\%}-5 \%$ missing. Abbreviations: Cons, conservative; Inv, invasive; CABG, coronary artery bypass graft; PCl, percutaneous coronary intervention; AMI, acute myocardial infarction.

events, and outcome between patients in the conservative treatment strategy group and those in the invasive treatment strategy group.

\section{The invasive treatment strategy is on the increase}

Even though the proportion of patients in the IG doubled between 2001 and 2007, we believe that $24 \%$ is still a low

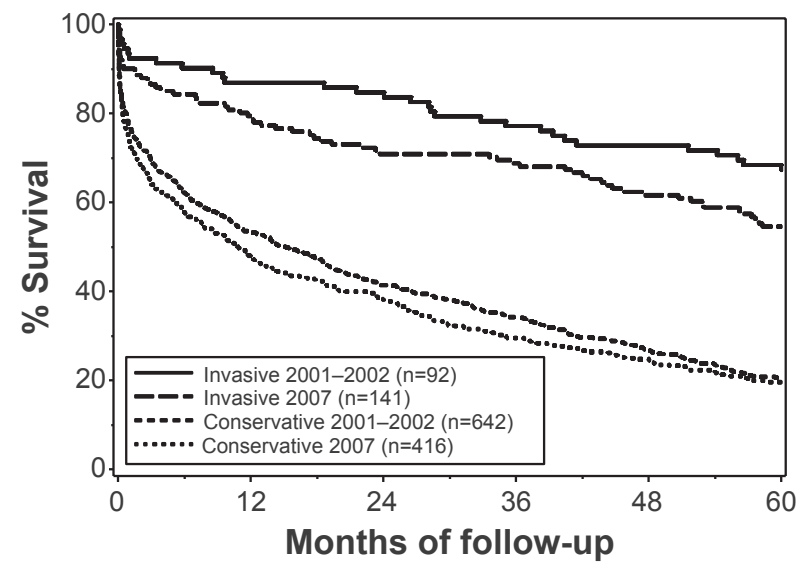

Figure I Kaplan-Meier curve describing survival in elderly patients with MI related to treatment strategy group.

Abbreviation: MI, myocardial infarction. percentage. A study from 2008 showed that elderly patients were less likely to undergo PCI than younger cohorts, and among the oldest ( $>80$ years old), $20 \%$ underwent PCI for NSTEMI and $30 \%$ for STEMI, which is in line with our results. ${ }^{9}$ More recent studies have also shown increasing PCI in the elderly, especially in STEMI patients. ${ }^{10,11}$ This could be due to increased availability of PCI, to physicians not discriminating against patients based on age and becoming more comfortable about performing procedures on the elderly, to the aging population in general, and to emerging evidence in favor of PCI. ${ }^{12,13}$ Still, practical risk-scoring systems should be developed to help clinicians and patients better understand the risks and benefits associated with the invasive treatment strategy in elderly people with MI.

\section{Heart failure}

Heart failure and cerebrovascular disease were common in elderly people who were not referred for a coronary angiography, which is in line with another observational study. ${ }^{14}$ One possible explanation would be that heart failure patients have higher levels of cardiac enzymes, especially elderly patients, and they more often have baseline ECG changes, making the diagnosis of MI more difficult. Another factor that could play an important role is uncertain benefit from 
revascularization due to myocardium that is considered to be non-salvageable. Elderly PCI-treated patients with low ejection fraction have a high risk of dying in hospital ${ }^{15}$ and a higher risk of complications with invasive procedures; thus, risk may outweigh benefit. A recent study showed high N-terminal of the prohormone brain natriuretic peptide (NTproBNP) a marker of heart failure measured in serum, to be an independent predictor of death in the elderly. ${ }^{16}$

\section{The groups differed in many ways}

The 5 year survival in the $\mathrm{CG}$ was worse than in the $\mathrm{IG}$, which is to be expected because of the higher age and competing risks due to other diseases, as we have shown. Even in the multivariate analysis where we adjusted for potential confounding factors in order to minimize selection bias, the result was similar. Our data therefore suggest that the invasive treatment strategy is associated with better outcome. But the purpose of our study was not to be able to recommend one treatment strategy over the other. That must be addressed with a proper randomized clinical trial.

Surprisingly, previous history of cancer and renal disease did not turn out to be statistically significantly different in the IG and the CG. This finding could be based on the low incidence rates thus the power to detect smaller differences in these cases are lower.

Physical frailty has gained more attention and has been associated with bad outcome in STEMI, ${ }^{17}$ but is thought to be observer-dependent, with risk of misclassification. In the present study, no information on physical frailty was available.

\section{Challenges and future opportunities}

Dedicated randomized clinical trials in the elderly have been difficult to complete due to slow enrollment. ${ }^{1,18}$ Also, numerous differences have been observed between elderly patients enrolled in community studies and clinical trials: trial patients are younger, they have lower prevalence of traditional risk factors, they have fewer comorbidities, they have less renal failure, and they have better hemodynamics. ${ }^{19}$ Thus, observational and community studies still remain important when trying to study clinical outcomes and practices in patients of high age. But, as touched upon before, this group can be difficult to study due to heterogeneity and risk of bias.

\section{Strengths of the present study}

The strength of this study is that we included all the elderly patients who were hospitalized for MI within a certain catchment area and gathered detailed information on these patients. The patients were not selected through admission to a specialized cardiology department, through inclusion in a randomized clinical trial, or due to the fact that they had undergone a coronary intervention. In addition, patients were identified and information regarding mortality was collected by using Swedish registries - which have very few data missing, a high degree of quality control, and high validity.

\section{Limitations of the study}

The limitations of this study are the retrospective collection of data and the fact that the final diagnosis of MI had not been scrutinized. There was some missing data, most importantly, ECG recording was available in 46\%-85\% of the patients. For this reason, we could not subdivide the groups according to acute coronary syndrome subgroup (STEMI, NSTEMI). We did not have any information about the cognitive status of the study participants, which made it impossible to calculate the comorbidity index. Also, elderly patients who died from acute MI before reaching hospital were not included. There turned out to be fewer patients in the 2007 group than in the 2001 group, and the reason for this is not known. We believe that at least two factors may explain this difference: 1) an overall lower incidence rate of MI patients in Sweden, ${ }^{20}$ and 2) more frequent screening for heart failure (with brain natriuretic peptide blood levels) in later years, which might result in more elderly patients being given a final diagnosis of heart failure, and therefore fewer being given a final diagnosis of MI.

\section{Conclusion}

Elderly patients with MI in the conservative treatment strategy group (no coronary angiography) were generally older and had more chronic diseases such as congestive heart failure and cerebrovascular disease than those in the invasive treatment strategy group. Our data suggest that the invasive treatment strategy is associated with better outcome. However, randomized trials are needed to determine whether revascularization procedures are beneficial in terms of less symptoms, better outcome, and improved quality of life in the elderly with MI. Such a trial is currently running in Sweden and is still recruiting patients. ${ }^{21}$

\section{Disclosure}

None of the authors have any disclosures relevant to the subject of this study. 


\section{References}

1. Savonitto S, Cavallini C, Petronio AS, et al. Early aggressive versus initially conservative treatment in elderly patients with non-ST-segment elevation acute coronary syndrome: a randomized controlled trial. JACC Cardiovasc Interv. 2012;5(9):906-916.

2. Kinnaird TD, Stabile E, Mintz GS, et al. Incidence, predictors, and prognostic implications of bleeding and blood transfusion following percutaneous coronary interventions. Am J Cardiol. 2003;92(8):930-935.

3. Gao L, Hu X, Liu YQ, Xue Q, Feng QZ. Percutaneous coronary intervention in the elderly with ST-segment elevation myocardial infarction. Clin Interv Aging. 2014;9:1241-1246.

4. No authors listed. Invasive compared with non-invasive treatment in unstable coronary-artery disease: FRISC II prospective randomised multicentre study. Lancet. 1999;354(9180):708-715.

5. Fox KA, Poole-Wilson PA, Henderson RA, et al. Interventional versus conservative treatment for patients with unstable angina or non-STelevation myocardial infarction: The British Heart Foundation RITA 3 randomised trial. Lancet. 2002;360(9335):743-751.

6. Lee PY, Alexander KP, Hammill BG, Pasquali SK, Peterson ED. Representation of elderly persons and women in published randomized trials of acute coronary syndromes. JAMA. 2001;286(6):708-713.

7. Ekerstad N, Lofmark R, Carlsson P. Elderly people with multi-morbidity and acute coronary syndrome: doctors' views on decision-making. Scand J Public Health. 2010;38(3):325-331.

8. Granger CB, Goldberg RJ, Dabbous O, et al. Predictors of Hospital Mortality in the Global Registry of Acute Coronary Events. Arch Intern Med. 2003;163(19):2345-2353.

9. Schoenenberger AW, Radovanovic D, Stauffer JC, et al. Age-related differences in the use of guideline-recommended medical and interventional therapies for acute coronary syndromes: A cohort study. $\mathrm{J} \mathrm{Am}$ Geriatr Soc. 2008;56(3):510-516.

10. Claessen BE, Kikkert WJ, Engstrom AE, et al. Primary percutaneous coronary intervention for ST elevation myocardial infarction in octogenarians: Trends and outcomes. Heart. 2010;96(11):843-847.

11. Velders MA, James SK, Libungan B, et al. Prognosis of elderly patients with ST-elevation myocardial infarction treated with primary percutaneous coronary intervention in 2001 to 2011: A report from the Swedish Coronary Angiography and Angioplasty Registry (SCAAR) registry. Am Heart J. 2014;167(5):666-673.
12. Bach RG, Cannon CP, Weintraub WS, et al. The Effect of Routine, Early Invasive Management on Outcome for Elderly Patients with Non-ST-Segment Elevation Acute Coronary Syndromes. Ann Intern Med. 2004;141(3):186-195.

13. Guagliumi G, Stone GW, Cox DA, et al. Outcome in elderly patients undergoing primary coronary intervention for acute myocardial infarction: Results from the controlled abciximab and device investigation to lower late angioplasty complications (CADILLAC) trial. Circulation. 2004;110(12):1598-1604.

14. Rittger H, Schnupp S, Sinha AM, et al. Predictors of treatment in acute coronary syndromes in the elderly: impact on decision making and clinical outcome after interventional versus conservative treatment. Catheter Cardiovasc Interv. 2012;80(5):735-743.

15. Batchelor WB, Anstrom KJ, Muhlbaier LH, et al. Contemporary outcome trends in the elderly undergoing percutaneous coronary interventions: Results in 7,472 octogenarians. J Am Coll Cardiol. 2000;36(3): 723-730.

16. Jaguszewski M, Ghadri JR, Diekmann J, et al. Acute coronary syndromes in octogenarians referred for invasive evaluation: treatment profile and outcomes. Clin Res Cardiol. Epub 2014 Aug 21.

17. Ekerstad N, Swahn E, Janzon M, et al. Frailty is independently associated with short-term outcomes for elderly patients with non-ST-segment elevation myocardial infarction. Circulation. 2011;124(22):2397-2404.

18. Lièvre M, Ménard J, Bruckert E, et al. Premature discontinuation of clinical trial for reasons not related to efficacy, safety, or feasibility. BMJ. 2001;322(7286):603-605.

19. Alexander KP, Newby LK, Cannon CP, et al. Acute coronary care in the elderly, part I. Non-ST-segment-elevation acute coronary syndromes: A scientific statement for healthcare professionals from the American heart association council on clinical cardiology. Circulation. 2007;115(19):2549-2569.

20. Socialstyrelsen [homepage on the Internet]. Myocardial Infarctions in Sweden 1988-2013. Sweden: Official Statistics of Sweden; November 2013. Available from: http://www.socialstyrelsen.se/ statistik/publiceringskalenderforofficiellstatistik/hjartinfarkter. Accessed November 13, 2014.

21. Libungan B, Hirlekar G, Albertsson P. Coronary angioplasty in octogenarians with emergent coronary syndromes: study protocol for a randomized controlled trial. Trials. 2014;15(1):349.
Clinical Interventions in Aging

\section{Publish your work in this journal}

Clinical Interventions in Aging is an international, peer-reviewed journal focusing on evidence-based reports on the value or lack thereof of treatments intended to prevent or delay the onset of maladaptive correlates of aging in human beings. This journal is indexed on PubMed Central, MedLine,

\section{Dovepress}

CAS, Scopus and the Elsevier Bibliographic databases. The manuscript management system is completely online and includes a very quick and fair peer-review system, which is all easy to use. Visit http://www.dovepress. com/testimonials.php to read real quotes from published authors. 